\title{
Evaluation of Openings Role from the Perspective of Wind Flow in Hot and Humid Climates (Case Study of Bushehr Seaport, Iran)
}

\author{
Parniaz Eskandari *, Ali Askar Rostami \\ New Idea Group of Architecture, Boushehr Branch, Islamic Azad University, Boushehr, Iran
}

Email address:

Eskandari_pz@yahoo.com (P.Eskandari), Rostamiali073@gmail.com (A. A. Rostami)

\section{To cite this article:}

Parniaz Eskandari, Ali Askar Rostami. Evaluation of Openings Role from the Perspective of Wind Flow in Hot and Humid Climates (Case Study of Bushehr Seaport, Iran).International Journal of Science, Technology and Society.Special Issue: Research and Practice in Architecture and Urban Studies in Developing Countries.Vol. 3, No. 2-1, 2015, pp. 58-63. doi: 10.11648/j.ijsts.s.2015030201.22

\begin{abstract}
Wind plays a decisive and effective role in designing of space among climatic factors that these factors influence can be found in some cities and many of the buildings. However between architectural elements, openings play an important role in thermal comfort through controlling the amount of the entry and exit of air (wind).As there is most need to use appropriate air draught in hot and humid climate, especially in Bushehr climate, so providing openings in favorable wind direction to lead cool air from the sea level to city is necessary. In this paper it is tried to evaluate the design of openings in harmony with climate area of study, by analytical methods in the field of science based on climatic conditions and reliance on data collection and scientific analysis of wind movement and behavior in this climate. These analyses will cause the openings to be designed so that they meet the admission of air flow (wind)in terms of lineup, form and number; so that the air draught in building create an impact in generating proper and ideal temperature for the users of space.
\end{abstract}

Keywords: Hot and Humid Climates, Wind Flow, Openings

\section{Introduction}

As in hot and humid climates one of the most important factors in human's discomfort is humid air and high temperature, air draught in space is necessary in some evenings and day hours, therefore, the building should be open to the cool breeze to provide the possibility of rapid cooling for internal spaces [1]. It is necessary to create an effective air draught in an area that people are present so all the rooms in building, should have opening parts, door or window in the pressure and suction region; or rooms that have windows just leeward or windward, should, by large openings, just enter the rooms that are on the opposite side of their pressure region [2]. The pressure that wind exerts on building surface is the result of wind's speed and angle toward its surface [3]. As the regional wind flow are different in various climates, it's important to consider prevailing and regional winds for wind effect on openings. Wind speed will decrease in hitting bumpy surface that are created by the form of buildings in cities [4]. Many studies have been done about the decreasing of wind speed in city; Giovanni quoted from lands berg, believed that roughness created by buildings in the wind direction is the most important reason by listing several reasons in this regard. He also quoted from Man that the winds were not distributed randomly in the city but they were distributed based on the ordering of the building blocks and street corridors are in the city [5].

The type of Window, the style of its opening, the height of installation and also their type and location of canopy have great influence on the shape and speed of air in the room. The place of exit window where the wind goes out doesn't affect the pattern of air movement in the room and it's just the height of installation place of air entry window that determines the pattern of air movement inside the room. Type of window openings also affects how air moves in the room [2]. Conditions of wind blow and its speed has a considerable impact on the design of the space in each region, and we can say the design of buildings and their openings whether in terms of their form and size or their arrangements can have an effective role on controlling the wind and its passage through interior spaces of building;[4]this issue has greater importance in areas with specific climate such as Bushehr, because in this region due to its location on a peninsula, the wind movement from different directions will lead the cool temperature from 
sea surface to the city, which causes a specific architecture specially in arrangement of openings in old texture of this area.

In this study hot and humid climate and especially Bushehr climate which is in northern bank of Persian Gulf and has particular climatic conditions in southern region of Iran is examined; after that the agent and direction of regional winds that are prevailing in this study area will be evaluated, therefore we can evaluate openings for the optimal use of winds in Bushehr climate on the basis of scientific analysis of data.

\section{Analytical Studies of Wind Flow}

Wind blow conditions are a factor that has great impact on thermal comfort in hot and cold areas (particularly hot and humid areas). Wind is an air flow that moves from high pressure centers toward the low pressure centers. If pressure gradient (pressure difference) between two points is greater, the severity of airflow will be increase [4].The most climatic factors that affect urban air conditions are regional winds. Regional winds are created due to the differences in atmospheric pressure, imbalance distribution of the solar radiation energy and its temperature and differences in air density [5]. These winds are blowing hundreds of meters above the surface so that wind speed slowly rises with increase of altitude and change of low temperature. The wind speed decreases near the earth surface and the wind motion involves great changes [4]. Winds are not distributed randomly in the city, but they flow based on the order of the building blocks and street corridors in the city [5]. The pressure that wind exerts on building surfaces is caused by wind blowing speed and its blow angle toward the surface. Pressure distribution on the surface depends on the size and dimensions of that surface [3].

Monsoons: Winds blowing in opposite seasons of the year in various directions; these winds blow from the land to the sea as a cold air flow in winter, and blow from the sea to the land as a warm moist air flow in summer. Sea and Land Breeze: These winds are the result of daily temperature difference between sea and land. During the day due to lowness of warmth relative temperature, the amount of sea air pressure is higher compared to the neighboring land. Hence an air flow will be created from the sea side into the land side. The land cools at night and a wind flow blows from land to the sea thanks to the air increase of their surface. Sea and land breezes will be changed by the total pressure of the atmosphere and wind systems [1].

Using Land to Sea and Sea to Land Breeze in summer: Sea coastal winds are different from dry winds. When light and hot breezes blow in summer, the coastal winds often blow in the opposite direction of overall mass of the air; Horizontal movements of air remove the difference in temperature, humidity and atmospheric pressure that exists in a horizontal direction, so the air comes into equilibrium state. Wind is a significant moderator in nature [4].

The amount of wind speed is important because of its impact on air temperature. Cooling effect of the wind that blows with the speed of $50 \mathrm{~km}$ per hour at a temperature below zero degrees $\mathrm{C}$ is in balance with sextuple of cold air with temperature of 12 degrees below zero [6].

\section{Bushehr Climatic Position}

The Bushehr peninsula is located on the northern coast of Persian Gulf with approximate dimensions of 20 in $8 \mathrm{~km}$. These coasts are included in hot and humid regions regarding to the climate. Summer is relatively long and winter is observed with relatively cool air just in two months, January and February; the annual temperature of Bushehr is an average of $6 / 24^{\circ} \mathrm{C}$, august and July, respectively, with an average of $2 / 33$ and $1 / 32^{\circ} \mathrm{C}$ are the hottest and January with an average of $1 / 15$ is the coolest month of the year. Closeness to the Persian Gulf has caused Bushehr to experience the humidity higher than 55 percent just in most months of year; and has more moisture in the first eight months of the year (known as sultry) (Figure 1) and (Figure 2) [7].

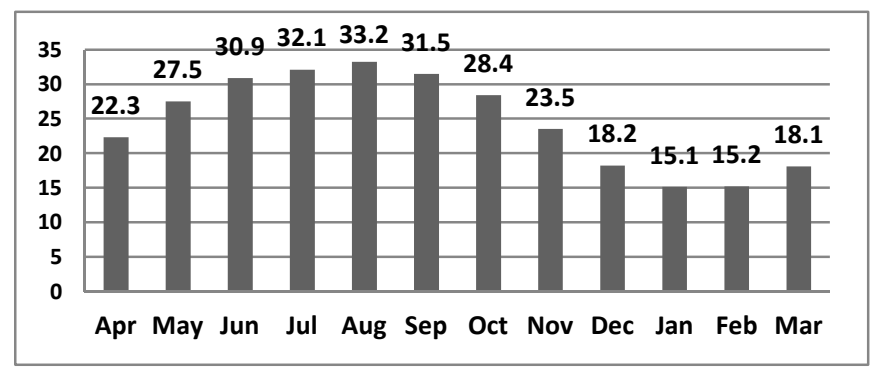

Figure 1. Diagram of the Long-term Average Temperature at Naval Station of Bushehr

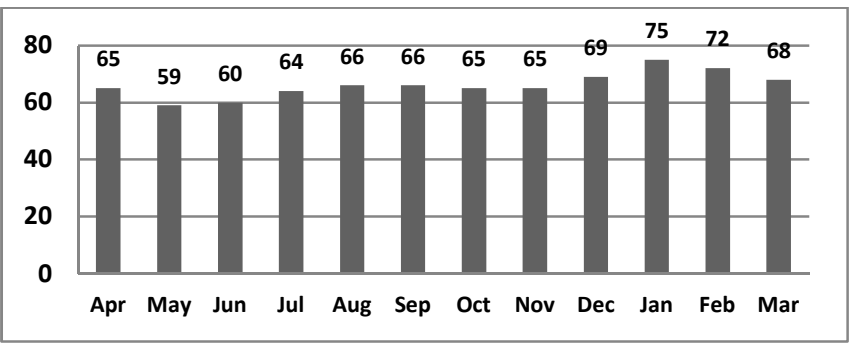

Figure 2. Diagram of the Long-term Average Moisture Naval Station at Bushehr

In examining the reasons and direction of created winds in Bushehr with considering its position to the sea, mentioning some factors is necessary:

A) Local winds of Bushehr province is in fact part of Persian Gulf storm that arises a result of the pressure difference between the Saudi desert and southern mountains of Iran in different reasons. The winds blow almost in all coasts of Persian Gulf that have different names in different parts of the Persian Gulf.

B) During the day the lands surface heats up faster than the sea water and air near the surface moves up due to its warming and lighting and the air near the sea gradually moves toward the land due to having less, cool and out weight temperature 
and get the place of light and warm air which moved upward. Thus during the day we will see a cycle of moving air or wind from the sea to land. It is obvious that in night this cycle is reverse.

C) In Bushehr, the famous north wind is the wind that blows from the North West and flow in the Tigris and Euphrates and will affect the Persian Gulf coasts from mid-October to early November. The speed of this wind reaches its maximum in the hottest month of the summer. This wind is the most famous local wind of Bushehr and is almost the only wind that somewhat moderates the warm weather in summer. North wind and sea breezes had the highest blowing percentage and its main direction is from northwest and especially in the summer from the west to east, that is, from the sea to land. Ghooyoob wind, Tariewind, Tobikh wind, Pirzan wind and Heptad wind are other local winds of Bushehr province [4].

\section{Scientific Analysis of Winds Conduct on Openings}

Although it's not necessary for an architect to know the physical methods for estimating the amount of air flow, it is essential to know the ways of increasing air flow.

\subsection{The Ways of Increasing Air Flow}

Direction change: the wind direction changes when hitting the building, but it returns to its original path after passing a distance. This process depends on the shape and dimension of the building.

Speed change: the wind's speed decreases in hitting to specific barriers depending on the barriers density (in level and height), so the wind speed increases with increasing the height, and getting away from the ground.

Create high pressure and low pressure areas: when the wind hits a barrier, a high pressure area in front and a low pressure area around and behind the barrier.

Passing thorough the openings: the wind doesn't enter if the building has an aperture windward but doesn't have any way out, though if the building has the way out, the wind enters from high pressure zone and goes out through low pressure zone [6].

\subsection{Performance of Wind Flow}

Ventilation: natural ventilation means using the displacement process of indoor air with fresh air from outside without using mechanical devices which reduces fossil energy consumption.

Ventilation by motion driving force: it is possible to use the wind flow for indoor air conditioning in two ways:

First method: using the same level openings (transverse ventilation or draught) which are at the same height level.

Second method: using the openings which aren't at the same level, in which two different levels of height are used for the entrance and propulsion of wind.

If the pores are at the same level, the best ventilation is possible when openings are placed on opposite sides. Second order ventilation occurs when the building has two openings on adjacent sides. The minimum ventilation rate belongs to the buildings which has two openings on one side, on condition that the pressure difference is generated by creating height difference or vertical blades between two openings. When openings are placed in two different levels, the wind is guided into the building through the higher opening and leaves through another aperture [8].

Cooling: the wind flow can accelerate the heat exchange between the body and air with the help of convection process and as a result it causes cooling [6].

\subsection{The Position of Opening and Its Effect on Natural Ventilation State}

Window position toward the wind direction has large influence on the status of natural ventilation in the room. The most important principle of creating effective and usable ventilation is that the opening pats are placed in parts which are behind and facing the wind. The most proper ventilation occurs when the wind direction is inclined toward the window. The results of studies on existing buildings show that if a room has windows leeward or windward, when the wind blows perpendicularly to an open window, air enters the room through the window windward and goes out directly and without changing direction through the window behind the wind. As a result, the points which aren't in the direction of air flow are not effectively affected by the airflow. When the wind flow direction toward the window is sidelong, almost each part of the room is affected by wind flow, and wind flows circularly along the walls and the corner of room. If the windows of a room are installed in the neighboring walls, the condition of natural ventilation is desirable when the wind flow direction is perpendicular to window. Assuming that desirable ventilation is resulted from perpendicular wind direction on the level of window, the building has to be built toward east or west to use wind power in creating natural ventilation. This type of standing especially in rectangular and long buildings causes many problems in terms of the creation of effective shade on windows of the two sides. Therefore, in these regions the best standing positions of building in terms of wind flow and sunrise contradict with each other. The so-called results show that in the regions in which desirable winds blow from west to east; appropriate ventilation can be created by 45 degree rotation of the main façade toward southeast or west east.[2]If desirable winds blow from northwest, northeast or southeast, desirable ventilation can be created by choosing the northern-eastern direction for the building.

Creation of blinds in rooms with one opening in outdoor wall: in normal conditions, if the windows of room are installed in just one outdoor wall, the amount of natural ventilation in the room is little. When wind blows in slope manner, air flows in a parallel manner and along the wall and creates a little pressure difference on its way and causes a flow creation from high pressure region to low pressure regions. We can use the pressure difference, and by installing two windows on the parts with more wind pressure and with less 
wind pressure, the conditions of indoor ventilation can be improved to some extent. Because the air pressure difference is low in this condition, the speed of air pressure is low in this situation. If a perpendicular blade is made on the outer level of the two windows, a pressure and suction region can be made artificially, so the speed of air increases in the room to some desirable amount. The existence of such blades around two windows causes the air to enter from one window and go out the other; the blinds are created in the room. In designing of buildings whose natural ventilation is deemed, considering perpendicular blades which cause both pressure area and to have other performance from architecture viewpoint, the same results can be made. For example, concerning doors and windows, we can create balconies by using perpendicular balconies along them; suitable conditions are created for the blinds [2].

The Effect of Window Size: The effect of window size in the conditions of internal ventilation depends much on the existence and non-existence of blind in room. The blind is created by wind when the leeward and windward walls have an open opening, in the rooms whose windows are installed in one part of the wall; the size of windows influences the speed of air to a little extent. Even when the size of air entry and exit window increases, the increase of air speed is not the same as the increase of windows size. If the windows of this room are changed in a way that the leeward window is bigger than the windward window, the peak and average of the speed of internal air augment to a large extent.

The Effect of Window Perpendicular Position on the Conditions of Natural Ventilation: although the airflow of a region is variable in horizontal levels to a large extent, the change of these winds direction in perpendicular levels is rather little. Because the free wind in the upper part of buildings is almost horizontal in all cases and its perpendicular direction change around a building with a geometric shape, with fixed features and setting is constant. Consequently, the speed of internal airflow in a room in different heights, depending on the position of window installment, has more constancy than its horizontal distribution; by designing and specifying the height of a room windows floor, the speed of air can be controlled to the fullest in the perpendicular level of that room. Thanks to the energy originated from wind movement, the shape of air mass movement in the room depends on the wind entry direction. So the height of a window floor and the kind of windward window opening has more importance in determining the direction and speed of wind movement in the room than features of wind exit position. In the domain of wind entry, the speed of wind suddenly decreases in the bottom part of window. The speed of air in the down part of window of rooms in which blind is created, the speed of main wind decreases to $25 \%$. Therefore, changing the height of the bottom part of window may change the speed of air in various heights to a large extent. But changing the average speed of the internal airflow of room has very little effect. For example, if the bottom height of window in the sitting room is more than the height of people in the sitting situation, the airflow is very little in the areas people sitting. In terms of the creation of natural ventilation in bedrooms, especially in high and dry areas in which we should make the most of wind flow, choosing the bottom height of window is of great importance.

The Effect of Direction and the Type of Window Opening: The way of opening, the height of installment position, and also the type and position of window canopy have great influence on the shape and speed of air in the room. To study the relationship between the howness of air movement in room and the relationship between the howness of air movement in the room and the bottom height of the air entry and exit windows and the effect of the canopy of windows, different examinations have been carried out whose results are as the following:

If the windward window is in the middle of wall and the leeward window is in the upper part of the window, the air moves toward the ceiling after entering the room and goes out through the leeward window. So the airflow will have no effect on the regions in which the habitants of the room are sitting.

If in this state in the upper part of the wall a horizontal canopy is installed, due to the selection of a higher tension area in the upper part of the window, the air flow is driven toward the floor. If in the upper part of the window a horizontal veil is installed low sided, again the air flow swerves to the roof. By maintaining these conditions if we change the location of wind exit window from top to down, the air is directed from the extreme end of room downward after striking the roof, going out of the exit window; that is, no changes occur in the form of air movement in the room. If the canopy and the window veil are removed, and the windward window is transferred downward, the air flow moves toward the floor and then to the exit window. This difference in the style of air movement is because in the previous state the air pressure in the upper part of the wall windward is more than the air pressure in the down part of window and therefore the wind diverts downward. If by maintaining the conditions in the upper part of the window a vertical canopy is installed, the wind swerves again toward the roof. In this state, by applying Venetian lattices in front of the window by creating a crack in the joint of canopy and wall the air flow can be directed downward. If Venetian lattices are removed, without the effect of the wind external window, the air flow swerves again toward the roof.

\section{The Designing Characteristics of Openings in the Optimum Use of Wind Flow in Bushehr Climate}

After the analysis of wind movement on windows and doors in this section, the properties and necessities of openings design to make an optimum and utmost use from the wind flow in Bushehr climate, we deal with the so-called analyses.

\subsection{Orientation}

One of the important patterns in a design proportionate to 
climate in architecture is the determination of position direction of openings in building; whose basis is the provision of light and transmission of proper air flow in construction, which is subject to some factors concerning the transmission of air flow. As mentioned, the Bushehr city is situated in a peninsula which is elongated from south to north and located in the sea like a nose and is located at the side of north, east and west, the more we move southward, the width of peninsula increases and on the east side the depth of water abates. In the design of construction, especially in this climate, after studying about useful and appropriate blind (blinding in north and east sides is inappropriate), it's time study orientation in terms of win flow (air). Experience shows that the north famous wind which blows from east to west, that is, from sea to land, is suitable due to directing toward the internal space of the construction. Considering the light and directing wind toward construction and our knowledge about different kinds of wind in the region, the best position of openings is the northern and western face of construction (Figure 3).

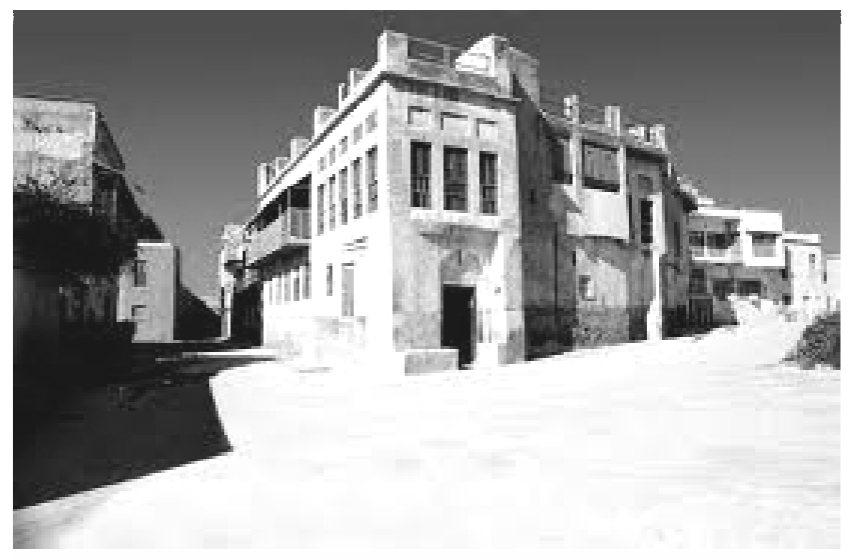

Figure 3. The way of openings arrangement [9].

\subsection{The Position Style}

Openings should be placed in a way that after the entering of wind from the main openings and the ventilation of internal spaces, it goes out from the openings installed on the other side of the construction. That is, wind enters form the high tension area and exits from the low tension area. It is suggested that by the creation of height difference in openings will influence the better enter and exit of air from internal space of building. That is, the peepholes of air enter should be installed higher than peepholes of air exit. Wind enters room naturally till the window of air entry is symmetrical in relation to ceiling and floor and exits from the exit window of air. Whenever the position of a window is asymmetrical in relation to the surrounding walls in face, wind gets into the room by diversifying from its main path; the scientific justification is that with the opening of window in face of building toward wind, the range of embolic pressure in front of the face is divided to smaller parts proportionate to wall extent around window (figure 3). Whenever the ranges around the air entry opening are symmetrical in relation to each other, wind flows in its main path; but if these ranges are asymmetrical, wind drives the larger range of air pressure toward the smaller range. Whereas the puff of wind in Bushehr is in height, the height of openings is suggested to be more in high tension area so that optimum use of wind would be possible (Figure 4).

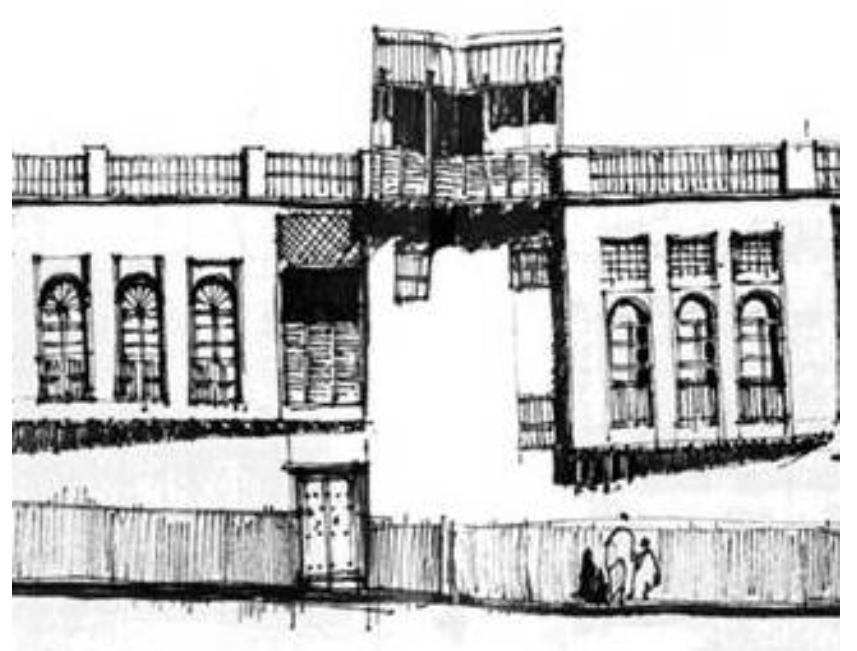

Figure 4. Bushehr old context-orientation of openings

\subsection{Form and Content, Dimension and Size}

In Bushehr the category of form and content of openings has been attended to by architects from the past, and because the design in past was subject to main elements of continent in this area of which the draught of air is one of the most important, as much as possible the making use of wind which has been the most important goal of architects in the past, is applied to form and content of openings. It's expected that by understanding and recognizing the principles of traditional pattern and considering the visual fixed ratios between the elements of the construction and whole construction, a form be created by the use of new methods and materials which is proportionate to the area and continent.

It's suggested that windows in Bushehr be installed with a linear form and apertures (openings) with little width and near each other, so that the shade of openings on each other leads to suction in high tension shell. The openings of windows should be dual in such a way that the dual part could be opened and closed; consequently when the speed of wind differs, the change of openings width would be controllable. The elongation of opening should be toward the roof; the most rational width of an opening is predicted to be 65 to $95 \mathrm{cms}$ so that the last margin would be installed in the border of internal space, also the projection of a part of external face or increase of windows depth will contribute to the process of suction in opening

\section{Discussion and Conclusion}

By summarizing the presented principles in the first part, 
the analysis of wind; and the second part, the clime of Bushehr city; and the third part, the scientific analysis of wind on building and openings; also the discussed issues in designing openings in Bushehr architecture proportionate to wind, it can be concluded that:

Whereas the Bushehr city which is situated in peninsula and has a little height difference; to exploit the climatic wind, the utmost effort has been made. In this clime, thence the sea wind direction toward land is diagonal in the afternoon, with increase of pressure difference between positive and negative ranges regarding the space openings; the speed of natural ventilation can be increased. Considering the study of pressure ranges around openings, we can analyze the effect of windows in the course of internal air flow; the desirable speed of wind in the entry of air flow from windows, in the course of internal air flow is very effective; whereas the direction of predominant wind is from northwest and west, to achieve better speed of air flow of internal space, space direction should be chosen in such a way that the joint axis of entry and exit of air along northwest and west acute angle be created. If there is a need for the flow of tangible air in room, the entry and exit windows of room air should be chosen tall so that the speed of internal air flow increases the $47 \%$ of the speed of external wind. Precision in selecting low width for openings aperture and high height and the position style of opening in depth causes the principles of Climatic design to be the source of building design and implementation so that in the seasons of the year where natural ventilation is possible, we can utilize the utmost of wind.

\section{References}

[1] M. Salighe, "The House Modeling Compatible with Climate for Chabahar City", Geography and Development, Vol. 20, 147-170, 2004.

[2] Kasmaie, Morteza, (2005), Tehran: Khak Publication

[3] D. Watson and K. Labs, Climatic Building Design: energy Efficint Building Principles and Practices; Mcgraw-Hill; 1993.

[4] E. Ranjbar,M. Pourjafar and K. Khaliji, " Innovations in Climatic Designing Due to The.

[5] B. Givoni, Climate consideration in building and urban design; Wiley \& Sons pub; New York; 1998.

[6] Wind Flowing Through The Old Bushehr", Baghnazar, Vol. 13 (7), 17-34, 2011.

[7] The Weather Organization, Data and Statistics of Bushehr Weather Station; 2013.

[8] Rah Shahr International Group, "The Role of Architecture Design in Reduction of Energy Consumption in Building (Wind Energy in Architecture)", No.129, 2011.

[9] Cultural Heritage Organization of Bushehr. The Pictures Collection of Old Texture of Bushehr; 2010. 